\title{
Das Libretto zur Oper Porsena von Agostino Piovene (Venedig 1712) als Vorläufer der Festa Teatrale Costanza e Fortezza von Pietro Pariati (Prag 1723)
}

The Libretto to the Opera Porsena by Agostino Piovene (Venice, 1712) as a Forerunner to the Festa Teatrale Costanza e Fortezza by Pietro Pariati (Prague, 1723)

Irena Veselá / Irena.Vesela@mzk.cz

Moravian Library, Brno, CZ

\begin{abstract}
The paper analyses and compares two italian librettos written in the 1st half of the 18th century: Agostino Piovene' libretto of the opera Porsena, performed in Venice during the carnival seasons of 1712 and 1713; and the libretto by Pietro Pariati written for the festa teatrale Costanza e Fortezza, performed in Prague in 1723 at the coronation of the Holy Roman Emperor Charles VI as King of Bohemia. Both librettos are inspired by historical events documented by the Roman historian Livy (59 BC - AD 17), recounting the overthrow of the last Tarquin king and the subsequent siege of Rome by Porsenna who tried to help restore the Tarquin dynasty and, according to Livy, failed to do so.

Before arriving at the Vienna court in 1714, Pariati lived in Venice and thus was probably familiar with Piovene's libretto. The paper argues that the differences between the two librettos are caused also by the fact that Pariati in his Costanza e Fortezza from 1723 adapted the characters as well as the overall tone of certain episodes to serve the current dynastic and political interests of Charles VI. The paper is based on the close reading of selected character lines, the main points of comparison being the characters and their portrayal, as well as different adaptations of particular episodes in both librettos. The most apparent differences between the two adaptations are understandably caused by the different genres (Piovene's dramma per musica being an opera seria, while Pariati's festa teatrale was rather a form of courtly entertainment written in celebration of a ruler). The deeper and more fundamental difference, though, lies in Pariati's implicit defence of the Pragmatic Sanction expressed through allegorical nuances in
\end{abstract}


the dialogue. One of the key differences, which upholds Charles VI's politics, is the Romans' adamant refusal of peace secured through marriage between the enemies of Rome and Roman girls in Costanza e Fortezza; while in Piovene's story, the Romans are willing to negotiate with their enemies about a marriage offer. The other key difference, perhaps surprising in the context of the Habsburg rule, is the Costanza e Fortezza's greater emphasis on the concept of republican freedom that the Romans gained in opposition to the tyranny of the Tarquin dynasty. The paper will explain the particular emphasis on these themes in Pariati's work, in light of the political situation in which it was written.

The paper builds upon the authors previous study The Giovanni Bononcini's Opera Muzio Scevola (1710) and the Johann Joseph Fux' Festa teatrale Costanza e Fortezza (1723). From a Music Dramma to an Allegory published in 2018 in the Supplementum to the journal Musicologica Brunensia.

\section{Key words}

18th century opera, festa teatrale, Porsena, Costanza e Fortezza, Agostino Piovene, Venice, 1712, Pietro Pariati, Prague, 1723, Emperor Charles VI. (1685-1740), Empress Elisabeth Christine von Braunschweig-Wolfenbüttel (1691-1750), Muzio Scevola, Nicolò Minato, Silvio Stampiglia, Vienna, Titus Livius, pragmatic sanction

Die vorliegende Studie gehört zu jenen, die verschiedenen Bearbeitungen historischer oder mythologischer Themen in den im 17. und 18. Jahrhundert entstandenen Opernlibretti nachgehen und sie vergleichen. ${ }^{1}$

Die von dem römischen Historiker Titus Livius (59 v. Chr. - 17 n. Chr.) in seinem umfassenden Werk Ab urbe condita dargestellte Kriegsgeschichte Roms mit dem Etruskerkönig Porsenna, der Stoff der von uns behandelten Oper, ist in Wahrheit eine reine national-römische Fälschung: Nach ihr hätten die Römer die bis dahin herrschende Königsdynastie der Tarquinier im Jahre 510 stürzen und eine Republik mit den Konsuln und dem Senat an der Spitze geschaffen. Die Tarquinier hätten sich an Porsenna (in den Libretti auch als Porsena) um Hilfe gewandt, der versucht habe, die Stadt Rom zu erobern und die Tarquinier wieder zu installieren, doch ohne Erfolg. Tatsächlich hat Porsenna im Jahre 507 v. Chr. Rom erobert. ${ }^{2}$

Diese den geschichtlichen Tatsachen keinesfalls entsprechende Darstellung, hat am Ende des 17. und im 18. Jahrhundert mehreren Librettisten als Vorlage gedient, wobei ihn jeder von ihnen zu seinem eigenen Zweck bearbeitet hat. Die vorliegende Studie ist

1 Vgl z. B. die Arbeiten: PELÍŠKOVÁ, Lucie. Armidy ve Vidni. Prolinání italských a francouzských prvků v tvorbě Tommasa Traetty, Antonia Salieriho a Christopha Willibalda Glucka [Armidas in Vienna. The interaction of Italian and French elements in the works of Tommaso Traetta, Antonio Salieri and Christoph Willibald Gluck]. Dissertationsarbeit, Masarykova univerzita, Brno 2008; MARCALETTI, Livio. Die keusche Penelope und der zornige Odysseus: Kursieren einer tragikomischen Opernhandlung zwischen Wien und Norditalien. Musicologica Brunensia 53, 2018, Supplementum, S. 85-97.

2 Konrad ZIEGLER und Walther SONNTHEIMER (hgg.), Der Kleine Pauly. Lexikon der Antike, Bd. 4, Deutscher Taschenbuch Verlag: München 1979, Sp. 1069-1070. 
Bestandteil einer Forschung, die sich auf das vom Hofpoeten Kaiser Karls VI., Pietro Pariati, für die Festa teatrale Costanza e Fortezza (Standhaftigkeit und Stärke) geschaffene Libretto konzentriert; die Oper wurde in der Vertonung durch Johann Joseph Fux am 28. August 1723, einige Tage vor der Krönung Karls VI. zum böhmischen König, aufgeführt. Der Titel des Werkes entspricht Karls lateinischer Devise „Constantia et Fortitudine“ (Mit Standhaftigkeit und Stärke [will ich regieren]) und den Intentionen seiner dynastischen Politik. Pariatis Version der von Livius erzählten Geschichte wird im Rahmen der Forschung mit zwei älteren Libretti auf das selbe Thema verglichen, und zwar mit jenem von Nicolò Minato für die Oper Mutio Scevola aus dem Jahr 1665 (sie wurde in den Jahren 1695 und 1710 von Silvio Stampiglia unter dem Titel Muzio Scevola bearbeitet) und dem Libretto von Agostino Piovene zur Oper Porsena aus dem Jahr 1712. Ziel dieses Vergleichs soll sein, Ähnlichkeiten oder Unterschiede in der Verarbeitung einzelner Episoden und in der Auffassung einzelner Charaktere zu finden. Schließlich soll festgestellt werden, inwieweit die Ähnlichkeiten oder Unterschiede auf die Absicht von Pariatis Auftraggebers, des Kaisers Karl VI., hinweisen, aufgrund eines bestimmten historischen Narrativs seine eigene dynastisch-politische Konzeption zum Ausdruck zu bringen.

Die Autorin dieser Studie hat bereits im Jahre 2018 einen Vergleich des Librettos von Nicolò Minato für die Oper Muzio Scevola, bzw. dessen jüngster Fassung aus dem Jahr 1710, mit dem Libretto Pietro Pariatis zu Costanza e Fortezza veröffentlicht. ${ }^{3}$ Auch das Thema der vorliegenden Studie wird im Vergleich des Librettos von Agostino Piovene zur Oper Porsena aus dem Jahr $1712^{4}$ mit dem zu Costanza e Fortezza nur teilweise auf Schlussfolgerungen aus den oben beschriebenen umfangreicheren Untersuchungen bringen, deren Ergebnisse Gegenstand einer künftigen Monographie werden sollen.

\section{Die Struktur der Handlung und der handelnden Personen in den Libretti}

Zuerst sei angemerkt, dass für alle drei von uns analysierten Libretti, also diejenigen von Minato, Piovene und Pariati, die drei wichtigsten Elemente ${ }^{5}$ der bei Livius dargestellten Geschichte über die Belagerung Roms durch die Etrusker dienten:

3 Ein Vergleich der Wiener Fassung des Librettos Muzio Scevola aus dem Jahr 1710 mit dem Pariatis zu Costanza e Fortezza aus dem Jahr 1723 war das Thema einer Studie der Autorin aus dem Jahr 2018; dort auch Verweise auf die weitere diesbezügliche Literatur. Vgl. VESELÁ, Irena. Giovanni Bononcinis Oper Muzio Scevola (1710) und Johann Joseph Fux' Festa teatrale Costanza e Fortezza (1723). Vom musikalischen Drama zur Allegorie. Musicologica Brunensia 53, 2018, Supplementum, S. 73-83.

4 [PIOVENE, Agostino.] PORSENA. Drama per musica Da rappresentarsi nel famosissimo teatro Grimani di San Gio: Grisostomo. Il Carnovale dell'Anno 1712. In Venezia. Appresso Marino Rosetti in Merceria all'Insegna della Pace. Con lic. de'sup. e privil. Zugänglich unter: https://archive.org/details/porsenadramaperm00lott?ref $=$ ol\&view=theater. Die zweite Ausgabe des Librettos erschien in Venedig für die Saison 1713, in der die Reprise der Oper stattgefunden hat: [PIOVENE, Agostino.] PORSENA. Drama per Musica Da Rappresentarsi nel Famosissimo Teatro Grimani di S. Gio: Grisostomo. Nel Carnovale dell'Anno 1713. Seconda edizione. In Venezia, MDCCXIII. Presso Marino Rossetti. In Merceria all'Insegna della Pace. Zugänglich unter: https://libretti. digitale-sammlungen.de/de/fs1/object/display/bsb00049021_00001.html?sort=sortTitle+asc\%2C+sortVolume+asc\&letter=P\&person_str=\%7BPiovene\%2C+Agostino\%7D\&mode=person\&context $=$.

5 Sie sind nach heutigem Wissensstand reine Legenden und sollten im Sinne des national-römischen Narrativs die Demütigung der Eroberung der Stadt mildern. 
1. Der Kampf der Etrusker und der Römer am Ponte Sublicio. Der Kommandeur der Wachen auf dieser von den Etruskern angegriffenen einzigen Tiberbrücke, war der Römer Horatius Cocles, d. h. „der Einäugige“ (Orazio). Er kämpfte, ein Beispiel für die altrömische Tugend der Tapferkeit, ganz allein, ließ, um zu verhindern, dass der Feind in Rom eindringe, die Brücke unter sich abreißen und sprang danach in den Tiber.

2. Der Mordversuch des Römers Gaius Mucius Scaevola, d. h. „der Linkshänder“ (Muzio), an dem etruskischen König Porsenna. Er hatte sich heimlich Zutritt in das etruskische Lager verschafft, um Porsenna zu erdolchen, jedoch irrtümlich statt ihm dessen Schreiber getötet. Vom König festgenommen und verhört, hielt Mucius, um seine furchtlose Vaterlandsliebe zu demonstrieren, während des Verhörs seine rechte Hand ins Feuer.

3. Der Flucht der Römerin Cloelia (Clelia) aus dem etruskischen Lager. Cloelia war eine der römischen Geiseln im etruskischen Lager. In einem unbewachten Moment schwamm sie mit anderen römischen Mädchen auf Pferden über den Tiber zurück nach Rom.

Wie bei Livius, endet die Geschichte in allen drei Libretti mit der freiwilligen Kapitulation Porsennas und einem für die Römer vorteilhaften Frieden. Alle drei oben genannten Heldentaten der Römer mussten die drei Librettisten nicht nur dramatisieren, sondern auch mit für die Zuschauer attraktiven Liebesgeschichten umrahmen. Es war für sie also nötig, in die Handlung eine bis zwei Frauengestalten zu integrieren; eine von ihnen ist in allen Fällen Tochter des römischen Konsuls Publius Valerius Publicola. Sie alle sind ausschließlich Römerinnen (Cammilla im Libretto Piovenes ist eine Ausnahme), die Porsenna und sein Hauptmann (Capitano) im besseren Fall in ehrlicher Gesinnung heiraten, im schlechten Fall mit Gewalt gewinnen wollen. Jede Römerin ist aber bereits verlobt bzw. verheiratet, und zwar mit einem der oben genannten römischen Helden, Muzio bzw. Orazio, und will ihrem römischen Verlobten (Ehemann) die Treue bewahren. Bei allen drei Librettisten spielt außer den nur einmaligen Heldentaten von Muzio und Orazio eine Rolle auch die ständige, unerschütterliche und schließlich auch erfolgreiche Gegenwehr der römischen Frauen gegen unerwünschte Freier und die Verteidigung ihrer Loyalität und Tugend.

Tab. 1: Übersicht der handelnden Personen in den Libretti zu den Opern Muzio Scevola und Porsena, und zur Festa teatrale Costanza e Fortezza:

\begin{tabular}{|l|l|l|l|}
\hline \multirow{3}{*}{$\begin{array}{l}\text { Handelnde } \\
\text { Person }\end{array}$} & \multicolumn{3}{|l|}{ Libretto (Ort und Jahre der Aufführung), Librettisten und Komponisten } \\
\cline { 2 - 4 } & $\begin{array}{l}\text { Muzio Scevola } \\
\text { (Wien 1710) } \\
\text { Nicolo Minato / Silvio Stampiglia } \\
\text { Giovanni Bononcini }\end{array}$ & $\begin{array}{l}\text { Porsena } \\
\text { (Venedig 1712 und 1713) } \\
\text { Agostino Piovene } \\
\text { Antonio Lotti }\end{array}$ & $\begin{array}{l}\text { Costanza e Fortezza } \\
\text { (Prag 1723) } \\
\text { Pietro Pariati } \\
\text { Johann Joseph Fux }\end{array}$ \\
\hline $\begin{array}{l}\text { König der } \\
\text { Etrusker }\end{array}$ & Porsenna & Porsena & Porsenna \\
\hline
\end{tabular}


The libretto to the opera Porsena by Agostino Piovene (Venice,1712) as a forerunner ...

\begin{tabular}{|c|c|c|c|}
\hline \multirow{2}{*}{\begin{tabular}{|l|} 
Handelnde \\
Person \\
Vertreter der \\
römischen \\
Dynastie der \\
Tarquinier
\end{tabular}} & \multicolumn{3}{|c|}{ Libretto (Ort und Jahre der Aufführung), Librettisten und Komponisten } \\
\hline & Tarquinio Superbo & 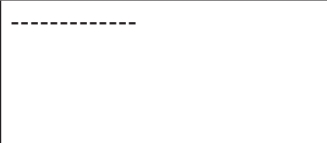 & Tito Tarquinio \\
\hline $\begin{array}{l}\text { Adjutant } \\
\text { (Hauptmann) } \\
\text { des etruskischen } \\
\text { Königs }\end{array}$ & Ismeno & Mesenzio & 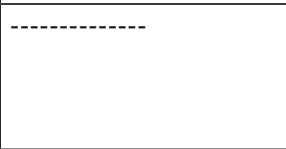 \\
\hline \begin{tabular}{|l|} 
Römischer \\
Konsul
\end{tabular} & Publicola & Valerio Publicola & Publio Valerio \\
\hline \begin{tabular}{|l|} 
Tochter des \\
Konsuls
\end{tabular} & Valeria & Clelia & Valeria \\
\hline \begin{tabular}{|l} 
Römischer \\
Bewerber um \\
die Tochter des \\
Konsuls \\
\end{tabular} & Muzio Scevola & Muzio Scevola & Muzio Scevola \\
\hline \begin{tabular}{|l|} 
Ein anderes \\
Mädchen (Frau) \\
auf der Seite der \\
Römer \\
\end{tabular} & Elisa & $\begin{array}{l}\text { Cammilla } \\
\text { (Prinzessin von Alba) }\end{array}$ & Clelia \\
\hline $\begin{array}{l}\text { Ihr römischer } \\
\text { Verlobter } \\
\text { (Ehemann) }\end{array}$ & Orazio & $\begin{array}{l}\text { Orazio } \\
\text { (abgelehnter Bewerber) }\end{array}$ & Orazio \\
\hline Gottheit & Flora & Tevere & Tevere \\
\hline Übrige & $\begin{array}{l}\text { Vitellia } \\
\text { (Tochter von Orazio und Elisa) }\end{array}$ & 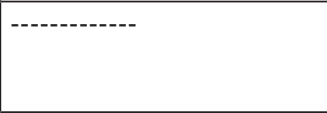 & \begin{tabular}{|l|} 
Erminio \\
(Sohn des römischen \\
Konsuls) \\
\end{tabular} \\
\hline
\end{tabular}

\section{Muzio Scevola}

Der älteste der genannten Librettisten, Nicolò Minato, hat sein Libretto zu Muzio Scevola vor allem als eine „weibliche Art“ des Kampfes gegen die Feinde aufgebaut. Er betonte das innere Leiden Valerias, der Tochter des römischen Konsuls, die am Anfang der Oper als Gefangene der Etrusker auftritt. König Porsenna verliebt sich in sie, er will sie als Gegenleistung für den Frieden mit Rom zur Frau erhalten, was ihm beinahe gelingt, weil der Konsul das Angebot Porsennas als einen Vorteil für Rom sieht. Die Standhaftigkeit Valerias und ihre Treue zu Muzio werden letztendlich siegen. Noch deutlicher beschrieb Minato das Leiden von Orazios ebenfalls gefangener Frau Elisa, die der Hauptmann Porsennas, Ismeno, auf eine sehr drastische Weise für sich gewinnen will. Trotz aller Widerwärtigkeiten, die sie erlebt, bleibt Elisa ihrem Mann treu und bereitet eine blutige Rache für Ismeno vor. Minato hat aber auch das langwierige innere Leiden Muzios nicht vergessen, der seine Liebe zu Valeria zugunsten des höheren Gutes, das Wohl des Vaterlandes, opfern muss, weil der Konsul im Interesse des Friedens dem etruskischen König seine Tochter zur Frau verspricht. Doch Porsenna zeigt sich als edelmütiger Gegner und 
als er erfährt, dass Valeria und Muzio sich lieben, wird er Valeria entsagen und mit den Römern Frieden schließen - obwohl Muzio kurz zuvor versucht hatte, ihn zu töten. Eine solche thematische Aufbereitung der Geschichte, in der weibliche Tugenden, bei unverheirateten wie auch bei verheirateten Frauen hervorgehoben wurden, war ein Thema, das auch im Jahre 1710 in Wien für die Namenstagsfeier der Ehefrau Kaiser Josephs I., Amalia Wilhelmine, geeignet war; zu diesem Anlass hat der damalige kaiserliche Hofpoet Silvio Stampiglia das Libretto bearbeitet. ${ }^{6}$

\section{Porsena - Einleitung}

Noch bevor wir das Libretto zu Porsena analysieren, ist es notwendig, auf den zeitlichen Kontext ihrer Entstehung einzugehen. Sie wurde im Jahr 1712 aufgeführt, weniger als zwei Jahre nach der Wiener Aufführung der Oper Muzio Scevola. Während dieser zwei Jahre hatte es auf dem europäischen Kontinent große politische Umwälzungen gegeben. Die Habsburger Österreichs führten seit dem Jahr 1701 den Spanischen Erbfolgekrieg mit den französischen Bourbonen und 1710 schien es, dass sie dem endgültigen Sieg bereits nahe wären. Erzherzog Karl, der jüngere Bruder Kaiser Josephs I., war 1703 zum König von Spanien proklamiert worden, und zweifelte nicht daran, dass er - und nicht sein Rivale, der bereits 1700 als Philipp V. ebenfalls zum König von Spanien deklarierte Bourbone Philipp von Anjou - mit der Unterstützung durch England, die Niederlande und Portugal das Erbe nach dem ausgestorbenen Zweig der spanischen Habsburger antreten werde können. Im Jahr 1711 ist jedoch der erst dreiunddreißigjährige Kaiser Joseph I. unerwartet gestorben. Weil er keinen männlichen Nachkommen hatte, hat Karl die Herrschaft in den habsburgischen Ländern angetreten und wurde am Ende des Jahres 1711 als Karl VI. zum römisch-deutschen Kaiser gewählt. So lag es bereits am Beginn des Jahres 1712 im Interesse der entscheidenden Weltmacht England, die Wiederherstellung der Habsburger Hegemonie, die das politische Gleichgewicht in Europa (balance of power) zerstören würde, zu verhindern und den Anspruch Philipps von Anjous auf den spanischen Thron zu unterstützen. Der Krieg, der mehr als zehn Jahre gedauert hatte, ging nun endlich zu Ende.

Der allgemeine Wunsch Europas nach Frieden fand unter anderem auch in der Oper Porsena von Antonio Lotti nach dem Libretto Agostino Piovenes seinen Ausdruck. Sie ist während des Karnevals 1712 im Teatro Grimani in Venedig uraufgeführt und dort ein Jahr später ebenfalls in der Karnevalszeit wiederholt worden. Kurz danach, am 11. April 1713, schlossen die bisherigen Alliierten der Habsburger (England, die Niederlande, Portugal, Preussen und Savoyen) auf der einen Seite, und Frankreich auf der anderen Seite, das Friedensabkommen von Utrecht. Im Anschluss daran, am 19. April 1713, erließ Kaiser Karl VI. die Pragmatische Sanktion, das habsburgische Erbfolgegesetz, demzufolge seine künftig zu erwartenden Kinder (auch die Töchter) den Vorrang vor den

6 Mehr zur Handlung dieser Oper bei VESELÁ, Irena. Giovanni Bononcinis Oper Muzio Scevola (1710) (siehe Anm. 3.). 
Töchtern seines verstorbenen Bruders Joseph, Maria Josepha und Maria Amalia, haben sollten. Damit verbunden war auch die Betonung der Unteilbarkeit der habsburgischen Länder. Im März 1714 wurde in Raststatt der Frieden zwischen dem Kaiser und Frankreich abgeschlossen und im September des selben Jahres in Baden (Kanton Aargau, Schweiz) ratifiziert. Erst mit diesem Akt war der Spanische Erbfolgekrieg endgültig beendet. Die Herrschaft im eigentlichen Spanien und in seinen überseeischen Kolonien verblieb bei König Philipp V., Mailand, Neapel, Sardinien und die spanischen Niederlande fielen an Österreich. ${ }^{7}$

Dazu sei noch bemerkt, dass sich zur Zeit der Aufführungen der Oper Porsena in Venedig (1712 und 1713) der künftige Hofpoet Karls VI. und Librettist der Oper Costanza e Fortezza, Pietro Pariati, in dieser Stadt aufhielt. ${ }^{8}$ Bis 1723, also dem Jahr der Entstehung des Librettos von Pariati, wurde Porsena nach dem Libretto Piovenes auch in den beiden neu erworbenen Besitztümern der Habsburger, in Neapel (1713) und in Mailand (1720), aufgeführt. ${ }^{9}$

\section{Porsena - Charaktere und Handlung}

Angesichts der oben beschriebenen Umstände, unter denen die Oper Porsena entstanden ist, ist es verständlich, dass der Librettist Antonio Piovene das Thema Frieden in den Vordergrund gestellt hat. Im Unterschied zu Minato hat er nicht die selbe Aufmerksamkeit der Präsentierung von Tugenden der römischen Frauen und ihrem Leiden gewidmet, auch nicht den Ausbrüchen der widersprüchlichen Emotionen von Muzio, der sich zwischen der Liebe zu seinem Vaterland und zur geliebten Frau bewegt. Bei Piovene nimmt einen größeren Raum die Politik ein, strategische Überlegungen, auch Staatsakte von stark symbolischem Gehalt, die das Bewusstsein der kollektiven Identität der Römer einerseits und Etrusker andererseits verstärken. Während im Libretto Minatos zu Muzio Scevola diese Episode aus der römischen Geschichte nur eine Kulisse für die Darstellung verwickelter Liebesbeziehungen und der demonstrativen Herausstellung von Tugenden bildet, handelt es sich bei Porsena bereits um den Kampf zweier Staatsordnungen und verschiedener politischer Systeme (Monarchie und Republik), in dem die Helden nicht nur für sich selbst, sondern vornehmlich im Interesse des Staates handeln. Und obwohl

7 Vgl. VLNAS, Vít. Princ Evžen Savojský. Život a sláva barokního válečnika [Prinz Eugen von Savoyen. Leben und Ruhm eines Kriegers des Barock]. Paseka-Národní galerie v Praze: Praha-Litomyšl, 2001, S. 446-457.

8 Im Jahr 1714 wurde Pariati Hofdichter und übersiedelte endgültig nach Wien. Vgl. SEIFERT, Herbert. Pietro Pariati poeta cesareo. In: GRONDA, Giovanna (ed.). La carriera di un librettista. Pietro Pariati da Reggio di Lombardia. Società editrice il Mulino: Bologna, 1990, S. 55.

9 Die Oper wurde im Teatro di S. Bartolomeo in Neapel am 19. November 1713, am Namenstag der Gattin Kaiser Karls VI., Elisabeth Christine, aufgeführt. Das Libretto Piovenes wurde für diese Gelegenheit umgearbeitet (die ursprünglichen Rezitative gekürzt, in die Handlung zwei weitere Personen eingeführt und einige der ursprünglichen Arien durch neue ersetzt). Die Musik Antonio Lottis hat der königliche Hofkapellmeister, Alessandro Scarlatti, dirigiert. Die Musik für die Aufführung im Teatro Ducale in Mailand im Jahr 1720 stammt vom dortigen herzoglichen Kapellmeister Giuseppe Vignati. Vgl. SARTORI, Claudio. I libretti italiani a stampa dalle origini al 1800. Cuneo: Bertola \& Locatelli, 1993, Bd. IV., S. 454. 
auch in Porsena der Römer Muzio in eine Situation gerät, in der er von widersprüchlichen Gefühlen zerrissen wird, lässt Piovene diesen einen viel geringeren Raum als Minato in seinem Libretto.

Um den rein politischen Sinn seines Librettos zu verstärken, musste Piovene vor allem den weiblichen Personen ganz andere Züge geben, als es vor ihm Minato getan hatte. Er führte die Römerin Clelia in die Handlung ein, über die bereits Livius schreibt, und machte aus ihr die Tochter des römischen Konsuls Publius Valerius Publicola. Clelia ist zunächst eine furchtsame junge Frau, doch nur auf dem ersten Blick - es wird sich noch erweisen, wie tapfer sie sein kann. Als Geliebten hat ihr der Librettist Muzio Scevola gegeben. Die zweite Frau in dieser Geschichte ist Cammilla, keine Römerin, sondern eine Tochter des Königs von Alba, ${ }^{10}$ die Porsena als Ehefrau versprochen ist. Zur Zeit der Belagerung durch die Etrusker wurde sie in Rom als Sklavin gehalten und sollte nach der Beendigung des Konflikts Porsena heiraten. Der Römer Orazio zeigt zwar einige Gefühle für sie, doch Cammilla lehnt ihn vom Anfang an ab. Sie ist stolz, zielbewusst, was die Rache betrifft, auch rücksichtslos, sehnt sich jedoch gleichzeitig auch nach Liebe. Auf der etruskischen Seite des Konflikts stehen zwei wichtige Personen der Handlung: der König Porsena und sein Hauptmann Mesenzio. Im Unterschied zu Muzio Scevola Minatos erscheint hier auf der Seite Porsenas kein Mitglied der verbannten Dynastie der Tarquinier, derentwegen der ganze Konflikt eigentlich ausgebrochen war.

Für die Hauptverwicklung der Handlung hat Piovene das Motiv der Verwechslung zweier Personen und der daraus entstandenen Missverständnisse verwendet, die für einige der Personen ein tragisches Ende nehmen.

Die Oper wird am Anfang des I. Aktes durch eine Kampfszene auf der Brücke über den Fluss Tiber, dem Ponte Sublicio, eröffnet. Der Römer Orazio kämpft hier ganz allein gegen die etruskische Übermacht. Auf seinen Befehl hin reißen seine Mitstreiter die Brücke nieder und Orazio springt in den Fluss, während ihn die Etrusker mit Pfeilen beschießen. König Porsena beendet den Kampf mit unverhohlener Bewunderung für die Tapferkeit des Feindes und erkennt gemeinsam mit seinem Hauptmann Mesenzio die Sinnlosigkeit, gegen einen so starken und so heldenhaft sich verteidigenden Feind weiteres Blut zu vergießen. Obwohl beinahe siegreich, will er Frieden schließen und gibt das dem römischen Konsul Valerio bekannt. Gleichzeitig fordert er von ihm als Geisel dessen Tochter Clelia, von deren Schönheit und Tugenden er gehört hat. Er wolle sie, falls sie ihm gefallen werde, auch heiraten. Cammilla, die ihm bereits versprochen war (und die er ebenfalls noch nicht gesehen hat) lehnt er ab. Mesenzio warnt den König vor einem unüberlegten Schritt: Der Frieden mit Rom sei unsicher und er werde, wenn er Cammilla ablehnt, den Zorn des Königs von Alba, ihres Vaters und seines Verbündeten, erregen. Der Konsul Valerio, der die Absichten Porsenas nicht kennt, nimmt sein Friedensangebot an und schickt zum Missfallen von Muzio und Orazio Clelia als Geisel, und ebenso Cammilla als Geschenk, in das etruskische Lager. Dem römischen Volk, das den Frieden und die Freiheit verlangt, wird er beides versprechen und lässt eine öffentliche

10 Gemeint ist die von Ascanius, dem Sohn des Aeneas, gegründete Stadt Alba Longa in Latium (jetzt Castelgandolfo). Sie wurde allerdings bereits unter den römischen Königen zerstört und ihre Bewohner in die Stadt Rom ausgesiedelt. 
Zeremonie als Friedensfeier veranstalten: Auf sein Geheiß liest Muzio vor dem versammelten Volk ein Dekret vor, das besagt, dass jedes Jahr an diesen denkwürdigen Tag der Vertreibung der Tarquinier aus Rom erinnert werden und bei dieser Gelegenheit ein gewählter Bürger eine Fahne der Freiheit hissen solle. Dadurch wird jedem deutlich gemacht, dass die einzigen Herrscher Roms weiterhin nur der Senat und das römische Volk seien. Der erste Bürger, der an dem bestimmten Ort die Fahne hissen darf, wird Orazio sein, der tapfere Held des Kampfes auf der Brücke.

$\mathrm{Zu}$ Beginn des II. Aktes hört Porsena auf Mesenzios Warnung und beschließt, den Bündnis mit dem König von Alba nicht aufzugeben. Um den Eindruck zu erwecken, dass er dessen Tochter Cammilla als seine Frau akzeptiert, greift er zu einer List: Er lässt Mesenzio auf seinem Thron im etruskischen Lager Platz nehmen und sich vor beiden Frauen, Clelia und Cammilla, für den König ausgeben. Er selbst spielt dabei die Rolle seines eigenen untergebenen Hauptmanns. Mesenzio empfängt in der Rolle des Königs die nichts ahnende Cammilla und führt sie in das Zelt hinein. Dann wendet sich Porsena an Clelia. Er bekennt, dass er der König der Etrusker sei und verspricht Clelia die Königskrone - unter der Bedingung, dass sie ihm gehören wird. Clelia, die eine Gefahr im etruskischen Lager geahnt hatte, weist ihn energisch zurück, und nutzt, nachdem sie Porsena verlassen hatte, die Gelegenheit zum Entkommen. Sie springt auf ein Pferd und überquert den Fluss zurück nach Rom. Nur Muzio entdeckt ihre Rückkehr und verbirgt sie vor dem Zorn des Konsuls. Unter dem Schutz der Nacht gibt sich Porsena für einen Abgesandten des etruskischen Königs aus und verlangt Clelia vom Konsul zurück nicht mehr als Geisel, sondern als die künftige Gattin des Königs. Der Konsul, der von der Rückehr Clelias nach Rom nichts weiß, weigert sich den Worten des vermeintlichen Abgesandten zu glauben; dieser andererseits glaubt nicht dem Konsul, dass er von der Anwesenheit seiner Tochter in Rom nichts wisse. Die Unterredung beider Männer wird schärfer, Porsena möchte im Namen seines Königs das Friedensangebot zurückziehen und den Konflikt wieder provozieren. Der Konsul beruhigt ihn und lässt Muzio rufen. Dieser wird den Grund von Clelias Flucht verraten: Es war die Zudringlichkeit eines etruskischen Hautpmanns. Schließlich erscheint Clelia und beschuldigt direkt Porsena. Dieser verteidigt sich und behauptet, er wollte Clelia im Namen seines Königs für diesen, als künftige Königin der Etrusker gewinnen. Trotz Muzios Einwänden schickt der Konsul Clelia zu den Etruskern als Geisel zurück und erklärt, dass über ihre eventuelle Vermählung mit Porsena der römische Senat bis zum Morgen entscheiden werde. Muzio will sich damit jedoch nicht abfinden und macht sich sofort auf den Weg ins etruskische Lager, um sich an Porsena zu rächen. In der selben Absicht begleitet ihn Orazio, dem Muzio verraten hat, dass Porsena Cammilla abgelehnt hat und nun Clelia heiraten wolle. Muzio behauptet auch, dass zusammen mit ihm dreihundert Römer einen Eid geschworen hätten, sich an Porsena zu rächen.

Mesenzio kann inzwischen im Lager der Etrusker der Versuchung nicht widerstehen, Cammilla für sich zu gewinnen. Die Tochter des Königs von Alba habe ihm auf den ersten Blick gefallen; wenn sie ihn erhöre, würde er darüber hinaus durch sie auch die königliche Würde erlangen. Er entschließt sich, gegen den Willen Porsenas zu handeln und verrät Cammilla, dass sie betrogen wurde, er sei nicht Porsena, sondern dessen 
Untergebener; der wahre Porsena sei in Rom, um Clelia zu gewinnen. Die wütende Cammilla verlangt nach Rache und Mesenzio bietet ihr an, diese selbst zu verwirklichen. Sie verspricht ihm ihre Hand dafür.

Die Handlung gipfelt im III. Akt in einer Zeremonie im Apollotempel auf dem von den Etruskern besetzten römischen Hügel Janikulum (Gianicolo). Die Etrusker bitten die Götter um ein günstiges Orakel für den Frieden mit den Römern. Clelia als Geisel soll die Fackel mit dem heiligen Feuer entzünden: Falls diese hell auflodern wird, sind die Götter dem Friedensschluss geneigt und die Etrusker sollen diesen durch einen Eid in die Hände ihres Königs besiegeln. Porsena beauftragt mit der Ausführung der Zeremonie Mesenzio, an dessen Seite Cammilla steht. Er selbst bleibt im Hintergrund. Das Orakel ist günstig und die Fackel in Clelias Hand brennt hell auf. Porsena tritt zu Mesenzio und gibt ihm die Weisung, als König von jedem Etrusker den Eid des Friedens abzunehmen. Muzio und Orazio mengen sich unter die Etrusker, die den Eid ablegen. Als Muzio zu Mesenzio kommt, zieht er im Glauben, es sei Porsena, einen Dolch und tötet Mesenzio. In der entstandenen Verwirrung wirft er den Dolch weg und ergibt sich den Etruskern. Sofort wird er mit dem echten Porsena konfrontiert und bemerkt erst jetzt, dass er nicht den König getötet hat. Er klagt laut über dieses Missgeschick und Porsena staunt über diese kühne Vermessenheit. Er will Muzio strafen, der aber kommt ihm zuvor: Er bestraft seine rechte Hand für ihren Irrtum und hält sie in das glühende Opferfeuer. Porsena, verblüfft über Muzios Kühnheit, befiehlt, ihn sofort vom Feuer wegzuziehen und abzuführen. Doch Muzio gelingt es noch ihm damit zu drohen, dass im etruskischen Lager dreihundert andere zur Rache bereite Römer auf ihre Gelegenheit warten. In diesem Moment bekennt auch Clelia, dass sie Porsena hasst; das selbe tut auch Cammilla. Diese offenbart Porsena, dass auch sie sich gemeinsam mit Mesenzio und dessen Anhängern für seinen Betrug und ihre Beleidigung rächen wollte. Wenn Muzio den Mesenzio nicht getötet hätte, hätte Porsena den Tempel nicht lebendig verlassen. Mit den Worten "Ich gebe auf und bin besiegt“ (Cedo, e son vinto - III. Akt / 9. Szene), bittet Porsena um Versöhnung - zuerst Clelia, die von ihm ihr Vaterland und ihren Verlobten zurück verlangt, und dann auch Cammilla, die jedoch, tief verletzt, mit ihrer Verzeihung zögert. Orazio sieht ihren Zorn, er will sie an seine eigenen Gefühle ihr gegenüber erinnern, sie verweigert jedoch auch seine Liebe. Schließlich wird sie Porsena doch verzeihen, und dieser wird sich mit Muzio versöhnen.

Am Morgen treffen alle Römer und Etrusker in einer öden Landschaft am Ufer des Tibers zusammen, wo nun eine Grenze zwischen ihren Territorien gezogen wird. Der Konsul Valerio erfährt von Orazio, dass Porsena nach Muzios Tat bereit ist, den Frieden sofort zu schließen, dass Muzio sich geirrt hat, weil er für den König einen anderen Mann gehalten hat, und dass jener Gesandte der Etrusker, der in der vorigen Nacht in Rom war, tatsächlich Porsena gewesen war. Dieser tritt nun zusammen mit Cammilla auf, und auch Muzio und Clelia erscheinen. Porsena bestätigt den Frieden mit Rom. Der Konsul umarmt ihn als Freund und zeigt sich, mit der Zustimmung des Senats, mit dem Wunsch Porsenas, Clelia zu heiraten, einverstanden. Doch Porsena erklärt, dass Clelia zu Muzio gehöre und das Schicksal ihm selbst Cammilla zur Frau bestimmt habe. Er fordert den Konsul auf, ein Zeichen zur Bekräftigung des Friedens zu setzen. Der Konsul 
stößt die heilige Lanze des Gottes Mars in den Boden und bestätigt so den Frieden und die gemeinsame Grenze. Porsena ergreift ebenfalls die Lanze und beide beschwören gemeinsam den Frieden.

Auf der Bühne öffnet sich eine Grotte und ihr entsteigt der Gott des Flusses Tiber. Die Äste der umliegenden Bäume bekleiden sich mit Silber und die ganze Szene leuchtet auf. Muzio sieht den Gott als erster und verkündet den anderen, dass dies ihr gemeinsamer Vater Tiber sei, der aus den Wellen gestiegen sei, um mit ihnen den Frieden zu feiern. Alle sehen das Wunder mit Staunen an und schwören dem Gott in einem Chor Frieden und Treue. Damit endet die Handlung.

\section{Porsena - Analyse der Handlung}

Zunächst widmen wir unsere Aufmerksamkeit einem bemerkenswerten Moment in der Handlung der Oper, das wahrscheinlich auf die damalige politische Situation in Europa Bezug nimmt, da es weder vorher bei Minatos Muzio Scevola, noch nachher bei Pariatis Costanza e Fortezza erscheint. Es handelt sich hier nämlich nicht nur um den Konflikt zwischen Etruskern und Römern, der im Interesse der verbannten römischen Königsdynastie der Tarquinier geführt wird, sondern um eine Auseinandersetzung, an der noch andere Seiten beteiligt sind. Die Herrschaftsansprüche der Tarquinier stehen völlig im Hintergrund, es scheint, dass sie Porsena nur als Vorwand zu seinem Kriegszug nach Rom gedient hatten. In dem Moment, in dem Porsena die Übermacht seines Gegners erkannt hat und der erwähnte Vorwand ihm nicht mehr von Vorteil ist, will er lieber sofort Frieden schließen. In seinem Heer befinden sich aber auch Bogenschützen des Königs von Alba, des mit ihm verbündeten Vaters von Cammilla. Eine momentane Laune Porsenas, nämlich sein Verlangen nach Clelia, wird dieses Bündnis zwischen den beiden Königreichen fast zerstören. Porsena kehrt schließlich zu Cammilla zurück und schließt gleichzeitig Frieden mit Rom. Die ursprüngliche Ursache des Konflikts, also die Ansprüche einer anderen königlichen Dynastie auf die Herrschaft in Rom, wird vollständig in den Hintergrund gedrängt. In dieser Verteilung von Mächten und Interessen spiegelt sich das Bild eines vielseitigen Konflikts wider, der zur Zeit der Abfassung des Librettos eine tägliche Realität war und deren Hintergrund ebenfalls dynastische Herrschaftsansprüche bildeten.

Ein ungemein wichtigeres Moment, das Piovene in der Oper betont, ist die Unvereinbarkeit der beiden gegensätzlichen politischen Systeme, der Republik und der Monarchie, worauf vor allem die römischen Akteure der Handlung hinweisen. Besonders die Gestalten des Konsuls Valerio, des Muzio und der Clelia erinnern wiederholt daran, dass die Römer mit den Königen schlechte Erfahrungen gemacht haben und eine Wiedereinführung der Monarchie es nicht mehr zulassen würden. Ihr Hass auf die Tarquinier wird auf alle anderen Könige übertragen, einschließlich Porsena. Für Clelia ist das, außer ihrer Liebe zu Muzio, der Grund, warum sie Porsena ablehnt, obwohl ihr dieser sein kostbarstes Gut bietet - den Thron und die Krone. Auch Muzio wirft dem Konsul vor, 
dass er die Möglichkeit einer Heirat zwischen Clelila und Porsena nicht von vorneherein ablehnt, und der Grund dafür ist nicht nur der Umstand, dass er selbst Clelia liebt. Er fragt den Konsul ganz offen, ob er wirklich wolle, dass das Blut, das dazu bestimmt sei, alles Königliche zu hassen, sich wieder mit einem Blut von Königen vereinigen würde (Clelia dunque sarà Sposa al Toscano? Dunque vedrassi il sangue, / Che ai Re nemico esser dovrebbe, e avverso, / Oggi al sangue dei Re di nuovo unirsi? - II/13). So wird der Konsul vor Porsena (obwohl dieser Inkognito auftritt) durch Muzio in die Enge getrieben und rettet seine Ehre nur, indem er erklärt, dass eine solche grundlegende Angelegenheit lediglich vom römischen Senat und nicht von einem Einzelnen entschieden werden dürfe. Auf diese Weise zeigt er Respekt vor den Institutionen der Regierung und der politischen Ordnung des republikanischen Rom - im Unterschied zum Konsul bei Minato in der Oper Muzio Scevola, der sofort beschließt, das Angebot des etruskischen Königs anzunehmen, ohne seine Entscheidung vom Senat überprüfen zu lassen.

Auch andere Gestalten in Piovenes Libretto sind sich der unüberwindlichen Barriere zwischen Republik und Königtum im Hinblick auf mögliche Ehen bewusst. Vor allem Clelia, die Porsena ganz offen sagt, sie sei eine Römerin und würde lieber als Bürgerin sterben, anstatt ihm als Königin ihre Hand reichen (Romana sono, e sappi, / Che più tosto morir vo'Cittadina, / Che stringer la tua man fatta Regina - II/4). Im III. Akt gibt sie ihrer hasserfüllten Verachtung gegenüber Porsena und königlichen Ehren in einer Arie Ausdruck (Odio, sprezzo, fuggo, e sdegno / Trono, affetti, onori, e Regno - III/1). Andererseits weist die Königstochter Cammilla die Gefühle des Römers Orazio vor allem deshalb zurück, weil er nicht von adeliger Herkunft ist. Für sie ist es erträglicher, als Königin in der Sklaverei zu sterben, als die Freiheit als niedrige Bürgerin zu erlangen (Più tosto vo'morir schiava Regina, / Che acquistar libertà vil Cittadina. - I/5). Auch am Schluss der Oper wählt Cammilla lieber den König, der sie vorher erniedrigt und beleidigt hat, als den Bürger Orazio, der ihre Beleidigung rächen wollte. Den römischen Helden wird ihre Überheblichkeit verletzen, aber er erkennt am Ende der Oper, dass eine Königin einen Bürger nicht lieben kann (Non poteva che alfine esser funesto / L'amor d'una Regina a un Cittadino.) und teilt allen Römern eine Lehre mit: „Liebt den Römer in Rom und hütet auch davor, außerhalb der Heimat ungleich zu lieben." (Ami in Roma il Romano, e dal mio esempio / A non amar fuor della patria impari. - III/13).

Am Ende seiner Oper ist Piovene von dieser geradlinigen politischen Linie der Römer jedoch abgewichen. Am Schluss des III. Aktes treffen sich in der Morgendämmerung an der neu gezogenen Grenze der Konsul Valerio mit Orazio, der diesem mitteilt, dass die Stärke Muzios (fortezza) Porsena so beeindruckt habe, dass er jetzt unter allen Bedingungen Frieden schließen wolle (O la di lui fortezza / Stordi Porsena in guisa, che già viene / Ad ogni patto a stabilir la Pace - III/12). Der Konsul ist daher jetzt in einer vorteilhaften Situation und könnte dem etruskischen König seine Bedingungen diktieren; anstatt dessen umarmt er Porsena und teilt ihm mit, dass der Senat dessen Vermählung mit Clelia genehmigt hat. Porsena jedoch, nach seiner eben erlebten Erschütterung, dass fast jeder in seiner Umgebung nach seinem Leben trachtete, ein zu besserer Einsicht gebrachter Gegner, überlässt Clelia dem Muzio und bietet seine Hand Cammilla an. Seine Entscheidung ändert er nicht, auch wenn der Konsul argumentiert, dass der Wille des 
Senats erfüllt werden sollte - obwohl dieser Wille dem in der Oper sonst proklamierten Geist der römischen Republik nicht entspricht. So wird Porsena schließlich selbst unwillkürlich zum Verteidiger der republikanischen Prinzipien der Römer. In diesem Moment handelt er wie der Etruskerkönig in Minatos Libretto zu Muzio Scevola. Piovene wollte mit dieser Szene wahrscheinlich zeigen, dass nicht nur Porsena, sondern auch die Römer dank dem Frieden und der Freundschaft mit den Etruskern dem Königtum nicht mehr feindlich gegenüber stehen. Aus unserer Sichtweise ist dieses Moment sehr wichtig: Eben dieser Gesinnungswandel der Römer gegenüber Porsena vermeidet später Pietro Pariati in seinem Libretto zu Costanza e Fortezza; darauf wird noch einzugehen sein.

Ein weiteres Schlüsselelement der Handlung bei Piovene ist der Frieden, besser gesagt der Frieden, der durch die Vermählung von König Porsena bedingt ist. Mit den Römern Frieden zu schließen, ist Porsenas Ziel vom Anfang an - er entscheidet sich für ihn gleich nach dem Kampf Orazios mit Etruskern am Ponte Sublicio in der 1. Szene des I. Aktes. Er denkt dabei ganz pragmatisch, er will, auch so knapp vor einem Sieg, seine Kräfte nicht mehr gegen einen so starken Gegner verschwenden. Er ist bereit, den Frieden durch die Heirat mit der Tochter des Konsuls zu besiegeln; im Unterschied zum Libretto Minatos führt ihn zu diesem Schritt nicht die Liebe, denn er hat Clelia bisher nicht einmal gesehen. Doch wenn sie ihm gefallen würde, könnte sie als Preis für den Frieden nützlich sein. (...se a me piace, / Clelia mia Sposa sia prezzo di pace. - I/2). Porsena weiß nur, dass er die - von ihm ebenfalls noch nicht gesehene - Cammilla nicht heiraten will. Am Beginn der Oper liebt er den Frieden mehr als Clelia, und seine Friedensliebe ist stärker als seine Abneigung gegenüber Cammilla (Più di Clelia, e Cammilla amo la pace. - II/1). Sein Hauptmann Mesenzio macht ihn auf mögliche militärische und politischen Konsequenzen aufmerksam, mit Recht befürchtet er den Zorn der Bogenschützen des Königs von Alba, die ja einen Teil der etruskischen Armee bilden. Die Erbansprüche der Tarquinier, der eigentliche Grund für die Belagerung Roms, sind zu dieser Zeit für Porsena nicht wichtig und es gibt in der Handlung keine Person, die diese Ansprüche verteidigt hätte (im Unterschied zum Libretto Minatos, in dessen Besetzung der verbannte römische König Tarquinio Superbo aufscheint).

Die zunächst pragmatische Einstellung Porsenas ändert sich im Laufe des II. Aktes. Nachdem Clelia seine zudringlichen Anträge abgelehnt hatte und aus dem etruskischen Lager nach Rom geflüchtet war, kommt er zum römischen Konsul bereits als ein verliebter Mann. Er glaubt, dass Clelia angesichts eines so großen Anreizes, das der Thron und die Krone einer ehrgeizigen Frau bieten würden, nicht widerstehen werde, sobald sie erfährt, dass er der echte König ist, und nicht Mesenzio (Clelia glaubt, wie auch zuerst Cammilla und später auch Muzio, dass Mesenzio der etruskische König sei). Bei dem nächtlichen Gespräch mit dem Konsul in Rom ist Porsena sogar bereit, das Friedensangebot zurück zu ziehen, wenn der etruskische König (für dessen Gesandten er sich ausgibt) Clelia nicht zur Frau erhalten werde. Er ist zwar dann bereit, die Gesetze der Römischen Republik zu respektieren und nach den Wünschen des Konsuls auf eine Entscheidung des Senats zu warten; doch die Rückkehr Clelias zu den Etruskern bedeutet für ihn nur, dass das Mädchen wieder in seiner Macht ist und sie ihm gehören wird, unabhängig vom Beschluss des Senats (Pesi il Senato pur l'utile, e il giusto, / Ma Clelia a noi 
ritorni: / Poi l'accordi il Senato, ò nieghi in Moglie, / Porsena non son io, se a me si toglie). Diese seine Absicht hält Porsena vor dem Konsul selbstverständlich geheim. Während der Zeremonie im Apollotempel finden die oben beschriebenen tragischen Ereignisse statt und Porsena fragt sich, ob diese Römer eigentlich Menschen oder vielmehr Götter seien: „Porsena, wo bist du? / Sind deine Feinde Menschen, oder Götter?“ (Porsena, dove sei? / I tuoi nemici sono Uomini, ò Dei? - III/9). Und er antwortet sich selbst: „Besser sich ergeben, weil meine Feinde so zahlreich und so stark sind“ (Ceder convien, che troppi, / E troppo forti sono i miei nemici. - III/9). Der König schließt also den Frieden letztendlich aus freiem Willen, ohne seinen Anspruch auf Clelia. Die mit der Lanze des Mars bestätigte gemeinsame Grenze wird zum Symbol des Friedens.

Ein weiteres, für den Vergleich mit Pariatis Libretto zu Costanza e Fortezza wichtiges Merkmal ist der Auftritt des personifizierten Gottes des Flusses Tiber. Diesen hat Piovene am Ende der Oper eingeführt, er erscheint als Deus ex machina, um als gemeinsamer Gott der Römer und Etrusker den neu geschlossenen Frieden zu besiegeln. Der Schluss der Oper ist jedoch nicht die einzige Gelegenheit seines wirksamen Auftretens. Als sich Clelia entschließt, sich zu Pferde in den Fluss zu stürzen, um aus dem etruskische Lager zu entkommen und nach Rom zurück zu kehren, ruft sie zuerst den Gott des Tibers in einem Rezitativ an und bittet ihn um seine Hilfe. Erst als sie sieht, dass sie die Wellen freundlich einladen und sie keine Angst haben müsse, überquert sie mutig den Fluss. Außer dem Tiber wirkt in der Handlung geheim auch ein anderer Gott, Apollo. Er tritt nicht als Person auf, sondern redet zu den Etruskern in seinem Tempel mittels eines Zeichens, durch die brennende Fackel in der Hand Clelias. So zeigt er, dass er den Frieden mit den Römern wünscht.

\section{Costanza e Fortezza - Gestalten und Handlung}

Noch bevor wir das Libretto Piovenes mit jenem von Pariati zu Festa teatrale Costanza e Fortezza vergleichen, soll noch gesagt werden, dass die Oper Porsena nach dem Libretto Piovenes (wie auch das zu Muzio Scevola von Minato) als dramma per musica angelegt ist, während Costanza e Fortezza als ein Huldigungswerk primär zur Feier des 32. Geburtstages der Kaiserin Elisabeth Christine in Prag im Jahr 1723 bestimmt war. ${ }^{11}$ Aus diesem Grund hat Pariati in die Handlung keine dramatischen Verwicklungen wie etwa Verwechslungen zweier Personen eingebracht, unter den Handelnden fehlt der vertraute Hauptmann des etruskischen Königs, der Teil der Besetzung bei Piovene (und vor ihm auch bei Minato) ist. Pariati hat aber in der Handlung als Gegner der Römer zwei Personen königlicher Abstammung benötigt. Deshalb hat er als Vertreter der aus Rom

11 PARIATI, Pietro. Costanza e fortezza, festa teatrale per musica da rappresentarsi nel reale castello di Praga per il ... giorno natalizio di Elisabetha Cristina, Imperatrice regnante ... Wien: J. P. van Ghelen, 1723. Die ausführliche Analyse der Handlung und der Musik siehe VESELÁ, Irena. Císařský styl v hudebně-dramatických dílech provedených za pobytu císaře Karla VI: v českých zemích roku 1723 [Der „Kaiserstil“ in den höfischen musikdramatischen Werken zur Zeit des Aufenthaltes Kaiser Karls VI. in den böhmischen Ländern (1723)]. Dissertationsarbeit. Masarykova univerzita: Brno, 2007, S. 66-140. 
verbannten Dynastie der Tarquinier deren Thronfolger Titus Tarquinius eingeführt, der gleichzeitig als vertrauter Helfer Porsenas auftritt. Der Gegenstand der Interesse der beiden sind zwei junge römische Frauen: die Tochter des Konsuls, Valeria (die bereits im Libretto Minatos erscheint), und die edle Römerin Clelia. Beide haben in Rom ihre Geliebten, die uns bereits bekannten Helden Muzio und Orazio. Muzio ist diesmal der Partner von Valeria (wie auch bei Minato), und Orazio (hier zum ersten Mal) jener von Clelia.

Die Römer denken - die Männer ebenso wie die Frauen - gleich, ihre Charaktere sind einander sehr ähnlich. Nur Muzio ist bei Pariati, wie bei Minato und Piovene, leidenschaftlicher und jähzorniger als die anderen, und wie im Libretto Piovenes entstehen die Konflikte zwischen ihm und dem Konsul wegen Valeria, dessen Tochter. Während für diesen sein Vaterland und dann erst seine Vaterliebe an erster Stelle stehen, schwankt Muzio als Römer und zugleich eifersüchtiger Liebhaber zwischen widersprüchlichen Gefühlen.

Auch im Libretto Pariatis finden drei heroische Taten statt: der Kampf Orazios auf dem Ponte Sublicio, der misslungene Versuch Muzios, Porsenna zu töten, gefolgt von der Selbstverbrennung seiner rechten Hand, und schließlich der Flucht des römischen Mädchens auf dem Pferd aus dem Lager der Etrusker über den Fluss Tiber. Clelia flüchtet bei Pariati aber nicht vor Porsenas Zudringlichkeit, sondern vor Tito Tarquinio.

Wie Piovene und vor ihm Minato eröffnet auch Pariati sein Werk mit einer Kampfszene unter Beteiligung der Chöre und Solisten. Hier handelt es sich jedoch nicht um den Kampf Orazios mit den Etruskern am Ponte Sublicio, sondern am Anfang stehen die Aufforderungen von Porsenna und Tarquinio an die römischen Gefangenen, sich ihrem Schicksal zu fügen, was diese ablehnen. Unter den Gefangenen ist auch die Tochter des Konsuls, Valeria, die sich in Porsennas Macht befindet. Porsennas verbale Drohungen enden in einem bewaffneten Angriff auf Rom, der jedoch vom aus den Wellen aufsteigenden Flussgott Tiber unterbrochen wird, der den Agressor warnt: Er soll den Fluss nicht an dem Tag überqueren, an dem die Göttin Vesta, die Beschützerin Roms, ihren Geburtstag feiert. Im Unterschied zu Piovene ist hier der Gott Tiber nicht der gemeinsame Vater der beiden gegnerischen Parteien, sondern lediglich der Beschützer der Römer. Der überraschte Porsenna zieht sich daher aus dem direkten Kampf zurück, gibt aber seine Absicht, Rom für Tarquinio zu erobern, nicht auf. Er meint, das Recht auf seiner Seite zu haben und sieht die Römer als Rebellen an, die ihren legitimen König verbannt haben und deshalb bestraft werden müssen. Als er erkennt, dass er mit Waffen nichts ausrichten kann, denkt er an die Möglichkeit einer friedlichen Lösung - er werde Valeria heiraten (er gesteht ihr sofort seine Liebe), und Tarquinio solle, in Rom erneut als König eingesetzt, Clelia erhalten. Er ignoriert die sofortige Ablehnung durch Valeria und schickt sie mit ihrem ebenfalls gefangenen Bruder Erminio nach Rom; sie soll ihrem Vater, dem Konsul, seine Friedensbedingungen überbringen. Die Römer in der Rolle dieser Gesandten sind uns bereits aus der Oper Muzio Scevola bekannt (in der in dieser unfreiwilligen Rolle Muzio auftrat).

Der Konsul Publio Valerio lehnt das Angebot Porsennas, zum Preis für den Frieden Tarquinio die Herrschaft über Rom zu überlassen und dies mit der Hand Clelias zu besiegeln, empört ab und bleibt bis zum Schluss der Oper auf diesem Standpunkt. 
Er schickt seine beiden Kinder aber trotzdem in die etruskische Gefangenschaft zurück. Wie im Libretto Piovenes, protestiert Muzio vehement gegen diese Handlung des Konsuls. Tarquinio sammelt inzwischen ungeduldig, und ohne Porsenas Wissen, eine Truppe von etruskischen Soldaten und versucht, mit ihnen den Fluss über den Ponte Sublicio zu überschreiten. Orazio beeilt sich, die Gefahr abzuwenden. Bevor er in den Kampf stürzt, kniet er am Ufer des Flusses nieder, ruft den Gott Tiber an und bittet um dessen Gunst - wie es Clelia im Libretto Piovenes vor ihrer Flucht aus dem etruskischen Lager getan hat. Der Grund ist offensichtlich: Der Librettist Pariati musste Orazio direkt mit Tarquinio in den Kampf gehen lassen, nicht nur als Verteidiger Roms, sondern auch als Verlobten von Clelia. Der Kampf verläuft nach dem gewohnten Szenario. Orazio befiehlt Muzio und den anderen seiner Mitkämpfer, die Brücke unter ihm abzureißen, was auch geschieht. Er fällt in den Fluss und wird durch die Göttin Vesta gerettet, die von den Römern gepriesen wird.

Der II. Akt hat Muzio zum Mittelpunkt. Er dringt unter dem Schutz der Nacht in das etruskische Lager ein und versucht, Porsenna zu töten, irrt sich jedoch und tötet anstelle des Königs dessen Schatzmeister, der den Soldaten den Sold auszahlt. Muzio wird von den Etruskern ergriffen und hält beim Verhör seine rechte Hand in das vorbereitete Opferfeuer. Porsenna ist von Muzios Tapferkeit, Standhaftigkeit und Stärke beeindruckt. In diesem Moment lässt Pariati den römischen Konsul Publio Valerio in das etruskische Lager kommen - dieses Motiv ist neu, in den Libretti von Minato und Piovene kommt es nicht vor. In Anwesenheit des Konsuls verzeiht Porsenna dem Muzio seine Tat. Publio Valerio lässt die römischen Geiseln bringen, unter denen sich Clelia und Orazio befinden, auch Muzio wird nunmehr zur Geisel genommen. Ähnlich wie im Libretto Piovenes teilt der Konsul seinem edlen Gegner (so wird Porsenna nach der Begnadigung Muzios bezeichnet) mit, dass über seine vorgeschlagenen Friedensbedingungen, nämlich die Thronbesteigung von Tito Tarquinio und die Heirat der beiden Könige mit den Römerinnen, der römische Senat bis zum Sonnenaufgang entscheiden werde. Dann verlangt Porsenna ein Orakel von seinen Haruspices (Aruspici), ${ }^{12}$ die aus dem Flug der Vögel am Himmel vorhersagen, dass die Vorzeichen für seine Absichten ungünstig stehen.

Im III. Akt bezieht sich die Handlung zunächst auf die Person der Clelia. Der listige Tito Tarquinio nutzt den Moment, in dem sich das Mädchen im Dunkel der Nacht allein in seinen Gärten auf dem Hügel Gianicolo befindet und versucht, sie in sein Zelt zu ziehen. Clelia verteidigt sich heftig und es gelingt ihr, ihm in einem unbewachten Augenblick das Schwert zu entreißen. Es tritt der Sohn des Konsuls, Erminio, auf, der Clelia heimlich liebt, begreift die Situation und will mit Tarquinio kämpfen. Clelia flüchtet und nimmt dabei das Schwert Tarquinios mit. Gemeinsam mit anderen gefangenen Römerinnen durchschwimmt sie dann auf Pferden den Tiber zurück nach Rom; im Unterschied zu Piovene hat Pariati diese Szene nicht direkt in die Handlung eingefügt. Als der Konsul Publio Valerio in der Morgendämmerung in die von den Etruskern besetzten Gärten am Gianicolo kommt, bringt er die geflüchtete Clelia mit. Er offenbart Porsenna,

12 Die Haruspices waren etruskische Priester, die hauptsächlich durch Leberschau und Blitzdeutung Weissagungen anstellten. Sie werden hier mit den römischen Augures verwechselt, die den Willen der Götter durch die Vogelschau festzustellen suchten. 
dass der römische Senat dessen Friedensbedingungen nicht gebilligt habe und dass Rom seine Freiheit auch um den Preis des eigenen Untergangs verteidigen werde. Der etruskische König soll nun zwischen dem nachteiligen Frieden und dem Krieg entscheiden. Die Helden befinden sich also am Ende der Handlung in der selben Situation wie am ihren Anfang. Von den Römern kann man kein Entgegenkommen erwarten. Sie verlangen von ihrem Konsul, den Krieg weiter zu führen, während die Etrusker ihren König um den Frieden bitten.

Porsenna ist aber nicht mehr der selbe wie früher. Während der drei Akte hatte er genug Gelegenheit, die Macht der Göttin Vesta sowie die Standhaftigkeit und Stärke der Römer kennen zu lernen, und als Clelia das erbeutete Schwert Tarquinios als Beweis der Niederträchtigkeit seines Besitzers vorzeigt, begreift er, dass sein Schützling keineswegs würdig ist, in Rom zu regieren. Er verstößt Tarquinio, entsagt schweren Herzens Valeria, und schließt mit den Römern den Frieden. Es bleibt nur, in der Licenza am Schluss zu offenbaren, dass die Göttin Vesta in Wirklichkeit die Kaiserin Elisabeth Christine verkörpere und mit Rom die böhmischen Länder gemeint seien.

\section{Costanza e Fortezza - Analyse der Handlung und Komparation mit dem Libretto zur Oper Porsena}

Es ist auf den ersten Blick offensichtlich, dass Pariati die Geschichte, abgesehen von einigen Verschiebungen in der Handlung und in der Zusammensetzung der Charaktere, ähnlich wie Piovene verarbeitet hat. Auch hinsichtlich der ideologischen Gesamtkonzeption des Konflikts ähnelt Costanza e Fortezza Piovenes Porsena mehr als dem älteren Libretto Minatos zu Muzio Scevola: Pariati konzentriert sich mehr auf die politische Seite des Konflikts als auf die Liebesbeziehungen und betont die Aversion der Römer gegen die despotischen Könige. Doch im Gegensatz zu Piovenes Libretto ist das Leitmotiv hier nicht die bloße Unvereinbarkeit zweier verschiedener politischer Systeme. Pariati betont ausdrücklich und wiederholt, dass Tyrannei und Freiheit miteinander unvereinbar seien - genauer gesagt, die Tyrannei, die die Römer durch den Sturz der Tarquinieer beseitigt haben, und die Freiheit, die sie durch die Gründung einer Republik erlangt haben und für die sie bereit sind, ihr Leben zu opfern. Und dies sei die Grundlage für ihre Standhaftigkeit und Stärke.

Daher wird auch das Wort „Freiheit“ (libertà) im römischen Sinne (nicht als persönliche Freiheit des Individuums) in Pariatis Text viel öfter verwendet als in dem von Piovene. In der Konzeption Pariatis wissen die Römer auch, dass sie ihre geliebte Freiheit nicht etwa durch einen ungleichen Kampf mit dem Feind verlieren könnten, sondern durch die Nachteile der Eheschließungen, die ihnen angeboten werden. Deshalb ist die Heirat von Porsenna mit Valeria und die von Tarquinio mit Clelia bereits von vornherein ausgeschlossen. Und deshalb wird der Konsul Publio Valerio (im Gegensatz zur Version der Geschichte bei Piovene und Minato) diese Möglichkeit keinesfalls zulassen. Sogar der Senat kann das römische Recht (le patrie leggi), das die römische Freiheit schützt, in 
dieser Hinsicht nicht überschreiten, selbst wenn er dies wünschte. Die Römer erklären in der Handlung, dass „unser Blut nicht zur Blüte der Tyrannen dienen kann“ (Il nostro sangue / Servir non puote a propagar tiranni - I/4), und „die römischen Töchter dürfen den fremden Königen keine Erben schenken“ (Figlie Romane / Dar non denno gli eredi a'Re stranieri - III/5). Dies bestätigt schließlich auch der Konsul selbst, als er den Willen des Senats interpretiert: Der Frieden nach Porsennas Wunsch verstoße gegen das römische Recht, und der etruskische König könne Valeria nicht zur Frau erhalten (Pace si vuol: ma da la pace intatte / Restin le nostre leggi. Al Re Porsenna, / Esse vietan Valeria - III/10).

Doch auch Porsenna, militärisch eindeutig stärker als die Römer, denkt zuerst, das Recht stehe auf seiner Seite. Denn es sei vollkommen rechtens, einem legitimen Herrscher, der von seinen Untertanen gestürzt und vertrieben wurde, zu Hilfe zu kommen und so zur Wiederherstellung der verletzten Ordnung beizutragen - und wenn nicht mit Gewalt, dann durch Heirat. Daher hätten die Römer und ihre Götter keine andere Wahl, als Porsenna davon zu überzeugen, dass es nicht widerrechtlich ist, einen Tyrannen zu stürzen - „wer die Tyrannei bekämpft, ist kein Rebell“ (Non è rubel chi a tirannia s'invola - I/1) sagt Valeria, die Tochter des Konsuls, bereits im I. Akt. Während sich Porsenna schließlich überzeugen lässt und den Frieden mit den Römern abschließt, ändert Tarquinio seine Meinung nicht und verliert daher schließlich alles: die Unterstützung Porsennas, die Hoffnung auf den Thron, und auch auf Clelia. Er bleibt vom Anfang an bis zum Schluss eine negativ besetzte Figur, eine Verkörperung der bereits einmal gestürzten Tyrannei, und sein Verhalten den Römern und insbesondere Clelia gegenüber, das alle Grenzen der Anständigkeit überschreitet, soll für Porsenna einer der wichtigsten Gründe werden, sich von ihm schließlich abzuwenden.

Wir haben diesen leicht zu übersehenden, aber grundlegenden Unterschied zwischen Pariatis und Piovenes Version der antiken Geschichte deshalb betont, um durch den Vergleich der Festa teatrale mit dem dramma in musica die Absicht zu erhellen, in der Kaiser Karl VI. im Jahr 1723 vor Hunderten hochgestellter in- und ausländischer Gäste ein Bühnenwerk aufführen ließ, das seine eigene Devise im Titel trug. Es wurde bereits mehrmals aufgezeigt, ${ }^{13}$ dass der Kaiser eben im Jahr 1723 mit den Bemühungen des sächsischen Kurfürsten und polnischen Königs aus dem Haus der Wettiner, Friedrich August, konfrontiert wurde, die Dynastie der Habsburger mit jener der Wettiner durch die künftige Vermählungen zweier seiner Töchter mit den Enkeln Friedrich Augusts zu verbinden. Diese beiden Enkel waren gleichzeitig auch Söhne der Nichte Karls, Maria Josepha, die aufgrund der Pragmatischen Sanktion bei ihrer Heirat mit dem damaligen sächsischen Kurprinzen Friedrich August im Jahr 1719 auf die österreichische Erbschaft hatte verzichten müssen. Ihr Schwiegervater, August der Starke, wollte diesen Umstand selbstverständlich nicht akzeptieren, wie auch der Schwiegervater ihrer jüngeren Schwes-

13 Vgl. VÁCHA, Štěpán - VESELÁ, Irena - VLNAS, Vít - VOKÁČOVÁ, Petra. Karel VI. a Alžběta Kristýna. Česká korunovace 1723. Praha-Litomyšl: Paseka-Národní galerie, 2009, S. 123-132. Dieselben. Karl VI. E̋ Elisabeth Christine. Die böhmische Krönung 1723. Frühneuzeit-Info, 21 (2010), S. 226-231. VESELÁ, Irena. „Venga quel Dì felice!“ Dynastisch-politische Botschaften der musikalischen Huldigungswerke für Karl VI. und Elisabeth Christine (1723). In TELESKO, Werner (hg.). Die Repräsentation der Habsburg-Lothringischen Dynastie in Musik, visuellen Medien und Architektur / Representing the Habsburg-Lorraine Dynasty in Music, Visual Media and Architecture 1618-1918. Wien-Köln-Weimar: Böhlau Verlag, 2017, S. 135-157. 
ter Maria Amalia, der bayrische Kurfürst Max Emanuel. Im Falle der Ehen zwischen den Habsburgern und den Wettinern würde der Nachwuchs der Tochter des verstorbenen Kaisers Joseph I. an die Regierung in den habsburgischen Ländern gelangen und gleichzeitig der Pragmatischen Sanktion Genüge getan. Diesen Absichten entsprechen die Allegorien im Libretto Pariatis: er hebt das Erhalten der Freiheit hervor - auch gegenüber den Angehörigen der vorher in Rom herrschenden Dynastie. Jeder, der beabsichtigt, ihr zur Regierung zu verhelfen und zugleich einen Vorteil daraus zu ziehen (z. B. durch die Hand der Tochter des Konsuls), sollte sich am Ende wie Porsenna verhalten - er soll vor der Standhaftigkeit und Stärke kapitulieren, die ihren Träger, Karl VI., auszeichnen, und vor der schützenden Göttin Vesta, die mit seiner Gattin Elisabeth Christine identifiziert wird. Vor allem aus diesem Grund kapituliert Porsenna bei Pariati nicht vor der Anzahl und Stärke der Feinde wie Porsena bei Piovene, sondern respektiert das Orakel seiner Haruspices, beugt sich vor den römischen Göttern, vor den römischen Tugenden und vor der großen Göttin Vesta, die die Römer glücklich sehen will (Si : voglio pace. I'cedo / De gli Aruspici a i detti, a'vostri Numi, / A la vostra virtude, e a la gran Dea, / Che felici vi vuol.) In diesem römischen Gesetz der Freiheit, das über den Anspruch souveräner Dynastien, die Herrschaft in ihrem Hoheitsgebiet aufrecht zu erhalten, triumphiert, wird wieder die Pragmatische Sanktion angesprochen. Auch der ihr zugrunde liegende Grundsatz der Unteilbarkeit der habsburgischen Länder spiegelt sich bei Pariati wider (wie bereits gesagt, vertritt Rom in der Oper die böhmischen Länder). Die Römer bilden unter allen Umständen eine Einheit - niemand, weder der Konsul noch sonst jemand anderer, wird vor Porsenna zurückweichen.

In diesem Zusammenhang betonte Pariati auch die Unverletzlichkeit des Territoriums Roms durch Porsenna und Tarquinio, und zwar ganz konsequent. Nicht nur, dass beide Angreifer die Stadt mit Gewalt nicht erobern, sondern auch darin, dass ihre Friedensverhandler den Tiber nie überqueren (nicht einmal unter einer falschen Identität wie der Porsena im Libretto Piovenes). Nur die Römer dürfen sich bei Pariati zwischen den beiden verfeindeten Lagern zu bewegen, einschließlich des Konsuls Publio Valerio, der bei Pariati zweimal ins etruskische Lager kommt, während er im Libretto Piovenes und im älteren Libretto Minatos die Grenze Roms nicht überschreitet.

\section{Zusammenfassung}

Wir können zusammenfassen: Im Vergleich zum älteren Libretto Nicolò Minatos zu Muzio Scevola in der Bearbeitung von Silvio Stampiglia aus dem Jahr 1710, die in der oben zitierten älteren Studie der Autorin analysiert wurde, zeigt das Libretto-Konzept Agostino Piovenes in der Oper Porsena mit Pietro Pariatis Libretto zur Festa teatrale Costanza e Fortezza viel mehr Berührungspunkte.

Doch nicht auf deren Grundlage, sondern im Gegenteil, aufgrund der Unterschiede zwischen den Libretti von Piovene und Pariati kann der Schluss gezogen werden, dass Costanza e Fortezza eine Verteidigung der Pragmatischen Sanktion in Form einer Alle- 
gorie darstellt. Das gleiche Ergebnis wurde einst durch den Vergleich des Librettos von Pariati mit denen der Opern Teofane ed Adelaide erzielt, die anlässlich der Hochzeiten der Nichten Karls VI. (1719 in Dresden und 1722 in München) aufgeführt worden waren (der Autor des Librettos zur ersteren war wieder Agostino Piovene). ${ }^{14}$ Beim Vergleich des Librettos zu Costanza e Fortezza mit den anlässlich der beiden Hochzeiten aufgeführten Opern waren die dynastisch-politischen Absichten in Form von Allegorien in allen genannten Werken leichter zu erkennen, weil bereits die Wahl der Themen und die zeitliche Nähe ihrer Entstehung ihren Zusammenhang aufzeigen. Doch erst der Vergleich von Pariatis Libretto mit dem zehn Jahre älteren Piovenes nach dem gleichen Stoff, das nicht nur für eine Aufführung vor dem Kaiserhof, sondern für die republikanische Venedig bestimmt war, erkennen wir, dass die Allegorien, durch die Pariati die dynastisch-politische Botschaft seines Auftragsgebers betont, sich in wesentlichen Details zeigen, die man jedoch leicht übersehen könnte. Deshalb nehmen wir an, dass Pariati das Libretto Piovenes nicht unbekannt war und er sich von ihm inspirieren hatte lassen (wie auch von der Wiener Fassung der Librettos von Minato zu Muzio Scevola aus dem Jahr 1710). Die mögliche Verbindung des Librettos zur Festa teatrale Costanza e Fortezza mit anderen Librettotexten aus jener Zeit wird Gegenstand weiterer Untersuchungen sein.

The paper was funded by the Institutional support for long term conceptual development of a research organization (The Moravian Library) by the Czech Ministry of culture.

\section{Bibliography}

\section{Sources}

Der MUZIO SCEVOLA. An dem Glorwürdigsten Nahmens-Tags Ihro Röm. Kayserl. Majestät Amaliæ Wilhelminæ, Auff Allergnädigsten Befelch Ihrer Röm. Kayserl. vnd Königl. Majest. Josephi Deß Ersten wälsch-gesungener vorgestellt ... mit der Music zu denen Worten des Giovanni Bononcini. Wien: Cosmerovische Erben, 1710.

PARIATI, Pietro. COSTANZA E FORTEZZA. Festa teatrale per musica da rappresentarsi nel reale castello di Praga per il ... giorno natalizio di Elisabetha Cristina, Imperatrice regnante ... Wien: J. P. van Ghelen, 1723.

[PIOVENE, Agostino.] PORSENA. Drama per musica Da rappresentarsi nel famosissimo teatro Grimani di San Gio: Grisostomo. Il Carnovale dell'Anno 1712. In Venezia. Appresso Marino Rosetti in Merceria all'Insegna della Pace. Con lic. de'sup. e privil. https://archive.org/details/porsenadramaperm00lott?ref $=$ ol\&view $=$ theater.

[PIOVENE, Agostino.] PORSENA. Drama per Musica Da Rappresentarsi nel Famosissimo Teatro Grimani di S. Gio: Grisostomo. Nel Carnovale dell'Anno 1713. Seconda edizione. In Venezia, MDCCXIII. Presso Marino Rossetti. In Merceria all'Insegna della Pace. https://libretti.digitale-sammlun-

14 Vgl. VÁCHA, Štěpán - VESELÁ, Irena - VLNAS, Vít - VOKÁČOVÁ, Petra. Karel VI. a Alžběta Kristýna, S. $170-172$. 
gen.de/de/fs1/object/display/bsb00049021_00001.html?sort=sortTitle+asc\%2C+sortVolume+asc\&letter=P\&person_str=\%7BPiovene\%2C+Agostino\%7D\&mode=person\&context $=$.

\section{Literature}

MARCALETTI, Livio. Die keusche Penelope und der zornige Odysseus: Kursieren einer tragikomischen Opernhandlung zwischen Wien und Norditalien. Musicologica Brunensia 53, 2018, Supplementum, S. 85-97.

PELÍŠKOVÁ, Lucie. Armidy ve Vídni. Prolináni italských a francouzských prvki̊ v tvorbě Tommasa Traetty, Antonia Salieriho a Christopha Willibalda Glucka [Armidas in Vienna. The interaction of Italian and French elements in the works of Tommaso Traetta, Antonio Salieri and Christoph Willibald Gluck]. Dissertationsarbeit, Masarykova univerzita, Brno 2008.

SARTORI, Claudio. I libretti italiani a stampa dalle origini al 1800. Cuneo: Bertola \& Locatelli, 1993, Bd. IV.

SEIFERT, Herbert. Pietro Pariati poeta cesareo. In: GRONDA, Giovanna (ed.). La carriera di un librettista. Pietro Pariati da Reggio di Lombardia. Società editrice il Mulino: Bologna, 1990, S. 45-71.

VÁCHA, Štěpán - VESELÁ, Irena - VLNAS, Vít - VOKÁČOVÁ, Petra. Karel VI. a Alžběta Kristýna. Česká korunovace 1723. Praha-Litomyšl: Paseka-Národní galerie, 2009.

VÁCHA, Štěpán - VESELÁ, Irena - VLNAS, Vít - VOKÁČOVÁ, Petra. Karl VI. Ẽ Elisabeth Christine. Die böhmische Krönung 1723. Frühneuzeit-Info, 21 (2010), S. 226-231.

VESELÁ, Irena. Císařský styl v hudebnè-dramatických dílech provedených za pobytu císaře Karla VI: $v$ českých zemich roku 1723 [Der „Kaiserstil“ in den höfischen musikdramatischen Werken zur Zeit des Aufenthaltes Kaiser Karls VI. in den böhmischen Ländern (1723)]. Dissertationsarbeit. Masarykova univerzita: Brno, 2007.

VESELÁ, Irena. Giovanni Bononcinis Oper Muzio Scevola (1710) und Johann Joseph Fux' Festa teatrale Costanza e Fortezza (1723). Vom musikalischen Drama zur Allegorie. Musicologica Brunensia 53, 2018, Supplementum, S. 73-83.

VESELÁ, Irena. „Venga quel Dì felice!“ Dynastisch-politische Botschaften der musikalischen Huldigungswerke für Karl VI. und Elisabeth Christine (1723). In TELESKO, Werner (hg.). Die Repräsentation der Habsburg-Lothringischen Dynastie in Musik, visuellen Medien und Architektur / Representing the Habsburg-Lorraine Dynasty in Music, Visual Media and Architecture 1618-1918. Wien-Köln-Weimar: Böhlau Verlag, 2017, S. 135-157.

VLNAS, Vít. Princ Evžen Savojský. Život a sláva barokniho válečnika [Prinz Eugen von Savoyen. Leben und Ruhm eines Kriegers des Barock]. Paseka-Národní galerie v Praze: Praha-Litomyšl, 2001, S. 446-457.

ZIEGLER, Konrad - SONNTHEIMER, Walther (hgg.). Der Kleine Pauly. Lexikon der Antike, Bd. 4, Deutscher Taschenbuch Verlag: München 1979. 
